\title{
Effect of electrical stimulation of the medial thalamus on neuronal activity of the thalamic ventrobasal complex in the anesthetized cat
}

\author{
Masanori OGATA, Kazuko NODA, Hisanao AKITA \\ and Sadao AIKAWA
}

\author{
Laboratory of Physiology, School of Allied Health Sciences, \\ Kitasato University
}

\begin{abstract}
The preceding companion paper reported the influence of stimulation of the centre médian nucleus (CM) of the thalamus on neuronal activity in the thalamic ventrobasal complex (VB). In the present study, a modification of the medial thalamus (MTh) except for the CM on activity in the somatosensory relay neurons of the thalamus was investigated in the cat. Extracellular multi-unitary discharges were recorded simultaneously from the VB using the multimicroelectrode system. The effects of MTh stimulation with a pulse train on VB neuronal activity were examined. The response of VB neuron to stimulation of other MTh nuclei were classified into the same four classes as that for CM stimulation: inhibited and then excited type; excited type; inhibited type; and non-responsive type. All four types of responses were observed in several nuclei of the MTh, such as the CM, central lateral nucleus (CL), mediodorsal nucleus (MD) and ventral posterior medial nucleus (VPM). MTh stimulation was more effective in nociceptive neurons than in non-nociceptive neurons. However, the effect of MTh stimulation differed among simultaneously recorded nociceptive neurons even when their receptive fields and recording sites were in close proximity. In some VB neurons, the response to stimulation applied to the center of the receptive field was also suppressed by MTh stimulation. Furthermore, an inhibitory effect on the response to stimulation applied to the periphery of the receptive field was observed even when the response to stimulation applied to the center of the receptive field was not inhibited by MTh stimulation. Thus, a large component of the MTh can modify VB neuronal activity and may be involved in the somatosensory system through complex mechanisms.
\end{abstract}

Key words: Thalamus, Ventrobasal complex, Medial thalamic nuclei, Electrical stimulation, Somatosensory system

\section{Introduction}

Thalamic nuclei have been classified into two groups according to the type of projection into the cerebral cortex; one group possesses a specific projection system with a more or less point to point arrangement and the other group possesses a non-specific projection system which projects diffusely ${ }^{11}$. The thalamic ventrobasal complex (VB) belongs to the specific system and plays a role in the somatosensory system as a synaptic relay of sensations including pain. Most nuclei of the medial thalamus (MTh) are included 
in the non-specific system. Neurons that respond to mechanical stimulation of the periphery have been observed in other thalamic nuclei such as the parafascicular nucleus (Pf), central lateral nucleus (CL), paracentral nucleus, central medial nucleus and Forel's fields ${ }^{21}$. Neurons in the posterior group, submedial nucleus ( $\mathrm{Sm}$ ) and centre médian nucleus (CM) are also involved in pain sensation ${ }^{3-5}$. Thus, the VB appears to be involved in the sensory discriminative aspects of pain, whereas the MTh mediates the motivational-affective aspects of pain ${ }^{6}$. An electrophysiological study using the anesthetized cats demonstrated that electroacupuncture altered nociceptive response patterns of neurons in the $\mathrm{CL}, \mathrm{CM}$ and $\mathrm{VB}^{7}$. Sumiya et al. ${ }^{8}$ reported an inhibitory effect of electrical stimulation of the Sm on the evoked EMG of the external oblique muscle elicited by colorectal distension. They also suggested that the $\mathrm{Sm}$ is not only one of thalamic relay nuclei of pain, but also, particularly in the ventral part, may be involved in a pain inhibitory system ${ }^{8}$. Although previous studies have demonstrated effects of MTh stimulation on VB neuronal activity, there are discrepancies in these reports ${ }^{3,9,10)}$. The preceding paper has shown that electrical stimulation of the $\mathrm{CM}$ in the MTh exerts not only inhibitory effect but also excitatory on VB neuronal activities, and the effects differ even among the simultaneously recorded units ${ }^{11}$.

In the present study, we investigate the effects of electrical stimulation of other MTh nuclei to clarify whether they also modify neuronal activity in the somatosensory relay neurons of the thalamus as CM does.

\section{Methods}

Experiments were performed on 64 adult cats (2.0 - $5.0 \mathrm{~kg})$. The animals were pretreated with an intramuscular injection of ketamine (20 $\mathrm{mg} / \mathrm{kg}$ ) and then anesthetized with an intraperitoneal injection of sodium pentobarbital (30 - $35 \mathrm{mg} / \mathrm{kg})$.

Extracellular multi-unitary discharges were recorded simultaneously from the VB using the multimicroelectrode system ${ }^{12}$. The receptive fields (Rfs) of VB neurons were stimulated with single electrical shocks at 2 or 5 times the threshold for $0.1 \mathrm{~ms}$ in duration. The MTh was stimulated with a train pulses ( 5 shocks at 500 $\mathrm{Hz}, 0.5 \mathrm{~ms}$ duration and $7-10 \mathrm{~V}$ intensity). The stimulating electrode of the MTh consisted of a bundle of 4 or 6 silver wires. Each silver wire had a diameter of $200 \mu \mathrm{m}$ and was insulated by enamel except for the tip. Separation between each tip was approximately $800 \mu \mathrm{m}$.

The atlas of the diencephalon by Jasper and Ajmone-Marsan ${ }^{13)}$ was used to identify the thalamic nuclei. In the atlas, the thalamic nuclei were clearly delineated with a solid line. However, delineation of these nuclei using only a histological technique is difficult. Therefore, effects of electrical stimulation applied to the thalamic area within the limits of the lateral 5.0 $\mathrm{mm}$ were regarded as effects of MTh stimulation. The details of experimental methods are described in the preceding companion paper ${ }^{11}$.

All data are expressed as mean \pm SD. Comparison of the number of neurons in each category was performed using the $\chi^{2}$ test. MannWhitney's U test was used to compare values with respect to the latency of the evoked discharge, the latency of inhibition of spontaneous discharge or the length of the inhibition (Stat View 4.5 for windows: Abacus Concept Inc.). Differences were considered significant at $\mathrm{p}<0.05$ level.

\section{Results}

\section{1) Classification of VB neurons}

One hundred fifty-four VB neuronal activities were isolated in 64 adult cats. The recording sites of the VB units ranged from Fr. 7.0 to Fr. 11.0. The Rfs of the majority of the VB neurons were 
localized on the contralateral side of the body with respect to the recording electrode. The VB neurons responded to mechanical stimulation of each Rf, and were then classified into 2 groups according to the responsiveness to noxious stimulation ${ }^{11}$. Eighty-one of the 154 units were considered to be nociceptive neurons and the form of mechanical stimulation that adequately excited them included pinching the skin with forceps. The remaining 73 units were classified as non-nociceptive neurons that responded to innocuous mechanical stimulation such as bending the hair and tapping the skin. These units did not show clear response to noxious stimulation ${ }^{11}$.

2) Effects of MTh stimulation on spontaneous activity of VB neuron

A total of 370 tests for response to pulse train stimulation of the MTh were performed on 154 neurons in the VB. Forty-five of the 154 neurons were only tested for their response to $\mathrm{CM}$ stimulation. Fifty-five neurons were tested repeatedly to determine their response to stimulation of the CM and other MTh nuclei. In the remaining 54 , the effects of stimulation of other nuclei in the MTh were examined.

Figure 1 shows responses of the unit to stimulation of three sites in the MTh including two sites in the CM and one site in the lateral posterior nucleus (LP). The unit exhibited excitatory response to stimulation of the dorsal portion of the $\mathrm{CM}$ with a latency ranging from 35 to $85 \mathrm{~ms}$, and did not respond to stimulation of the LP and the ventral portion of the CM.

The changes in neuronal activity following $\mathrm{CM}$ stimulation were divided into four classes ${ }^{11}$. Class 1 neurons exhibited inhibition of spontaneous discharge followed by excitation. Class 2 neurons exhibited only excitation. Class 3 neurons showed only inhibition of spontaneous discharge. Class 4 neurons did not respond at all to CM stimulation ${ }^{11}$. The response of VB neuron to stimulation of other nuclei in the MTh were also classified into

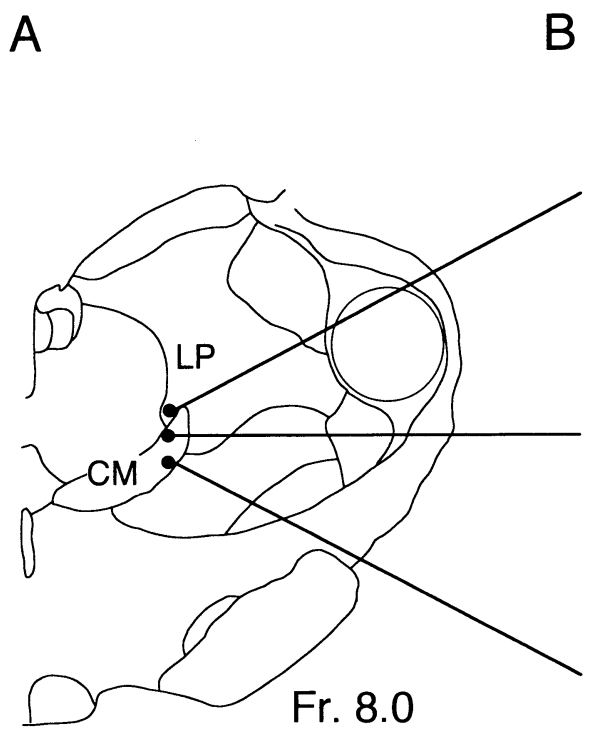

B
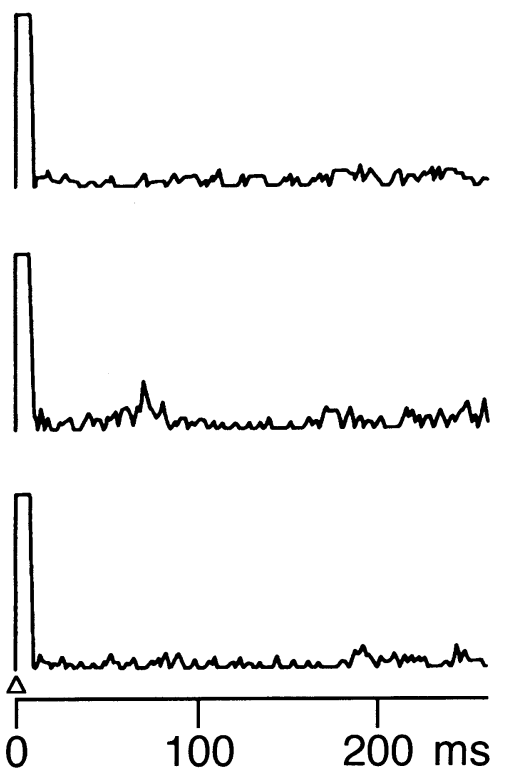

Fig.1 Responses of VB neuron to MTh stimulation

A : sites of stimulation in MTh. B : PSTHs of responses to MTh stimulation. Open triangle $(\triangle)$ shows point at which MTh was stimulated. Vertical bar indicates 20 spikes. Each PSTH represents average of 100 trials in this and following figures. Analysis time is $256 \mathrm{~ms}$ (bin width $=2.0 \mathrm{~ms}$ ). 
Class of
Response

1
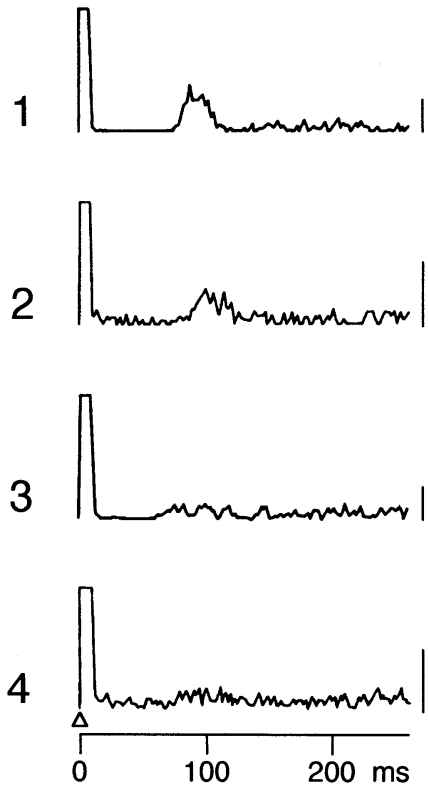

B

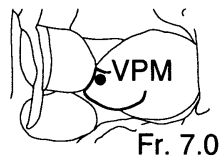

Fr. 7.0
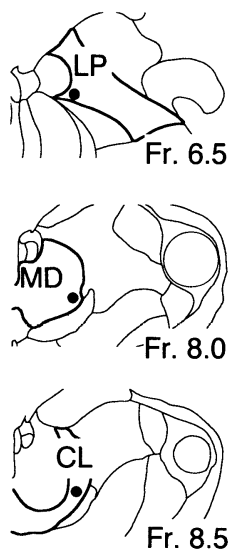

Fr. 8.5
C

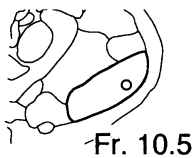

-Fr. 10.5
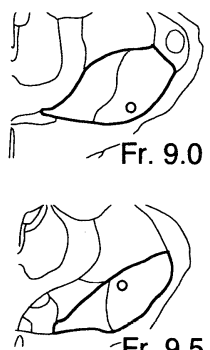

-Fr. 9.5

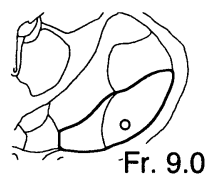

D
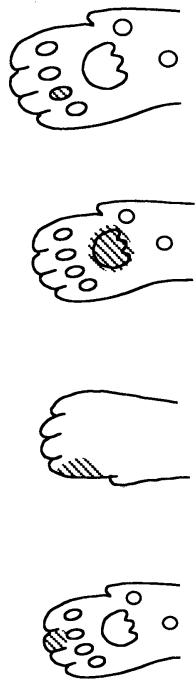

Fig.2 Classification of response pattern of VB neurons to MTh stimulation

Numbers on left indicate class of response. A: PSTHs of responses to MTh stimulation. Analysis time is $256 \mathrm{~ms}$ (bin width $=2.0 \mathrm{~ms}$ ). Open triangle $(\triangle)$ shows point at which MTh was stimulated. Vretical bars indicate 20 spikes. B and C: sites of sitmulation in MTh $(\mathbf{O})$ and recording sites in $\operatorname{VB}(\bigcirc)$. D: Rfs of each unit.

Teble 1 Number of each class of response to MTh stimulation

\begin{tabular}{|c|c|c|c|c|c|}
\hline \multirow[b]{2}{*}{ Stimulated Nucleus } & \multicolumn{4}{|c|}{ Class of response } & \multirow[b]{2}{*}{ Total } \\
\hline & Class 1 & Class 2 & Class 3 & Class 4 & \\
\hline $\mathrm{CM}$ & 39 & 26 & 29 & 115 & 209 \\
\hline $\mathrm{MD}$ & 2 & 4 & 5 & 39 & 50 \\
\hline VPM & 16 & 2 & 18 & 10 & 46 \\
\hline $\mathrm{CL}$ & 7 & 2 & 2 & 14 & 25 \\
\hline H1 & 3 & 0 & 4 & 5 & 12 \\
\hline LP & 0 & 1 & 0 & 10 & 11 \\
\hline NR & 1 & 0 & 0 & 6 & 7 \\
\hline Pf & 2 & 2 & 2 & 0 & 6 \\
\hline Spf & 2 & 0 & 0 & 2 & 4 \\
\hline Total & 72 & 37 & 60 & 201 & 370 \\
\hline
\end{tabular}

CL, central lateral nucleus; CM, centre médian nucleus; H1, forel's fields; LP, lateral posterior nucleus; MD, mediodorsal nucleus; NR, red nucleus; Pf, parafascicular nucleus; Spf, subparafascicular nucleus; VPM, ventral posterior medial nucleus. 
the same four classes. Figure 2 shows an example of these response classes. The latency of evoked discharge by stimulation of the MTh including $\mathrm{CM}$ was $111 \pm 62 \mathrm{~ms}$. In units that were only tested for response to $\mathrm{CM}$ stimulation (only CMtested units), the latency of the evoked discharge was $95 \pm 44 \mathrm{~ms}$. In only CL-tested and only ventral posterior medial nucleus (VPM) -tested units, the latency of the evoked discharge was $114 \pm 43 \mathrm{~ms}$ and $99 \pm 50 \mathrm{~ms}$, respectively. These data are not significantly different $(\mathrm{CM} \cdot \mathrm{CL}, \mathrm{p}$ $=0.1751 ; \mathrm{CM} \cdot \mathrm{VPM}, \mathrm{p}=0.9250 ; \mathrm{CL} \cdot \mathrm{VPM}, \mathrm{p}=$ 0.4062). The inhibitory period of spontaneous discharge induced by MTh stimulation was $65 \pm$ 36 ms. In only CM-tested units, the inhibitory period was $50 \pm 25 \mathrm{~ms}$, and $57 \pm 14 \mathrm{~ms}$ in only
CL-tested units. The inhibitory period in only VPM-tested units was $73 \pm 26 \mathrm{~ms}$, which is significantly longer than that of only CM-tested units $(p<0.05)$. The latency of inhibition of spontaneous discharge induced by MTh stimulation was $20 \pm 7 \mathrm{~ms}$ in the units for which latency measurement was possible. In only CMand VPM-tested units, the latency of inhibition was $16 \pm 6 \mathrm{~ms}$ and $20 \pm 5 \mathrm{~ms}$, respectively.

The relationship between the effects on VB neuronal activity and the stimulated nuclei in the MTh is shown in Table 1. No nucleus in the MTh showed only one class of response. All four classes of responses were observed in the CL, $\mathrm{CM}, \mathrm{VPM}$ and mediodorsal nucleus (MD). A comparison of the effects of CL, CM, MD and

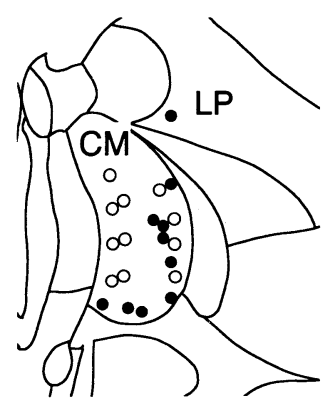

Fr. 6.5

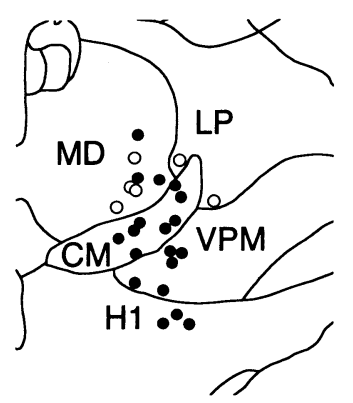

Fr. 8.0

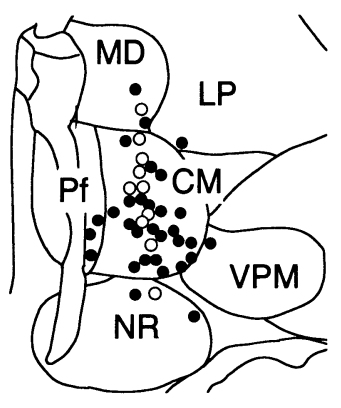

Fr. 7.0

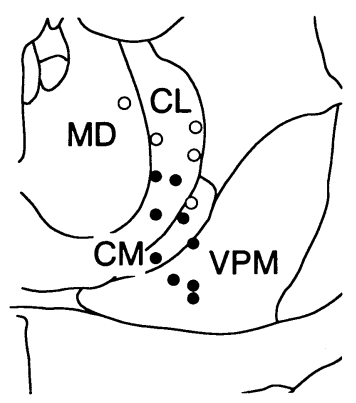

Fr. 8.5

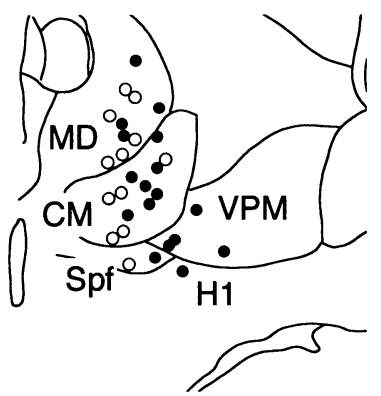

Fr. 7.5

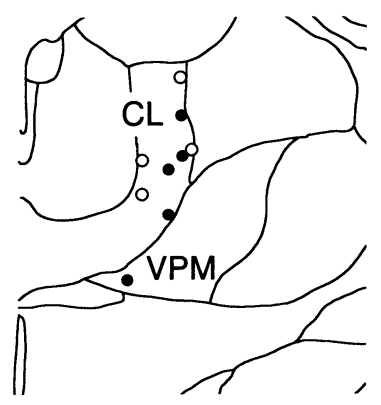

Fr. 9.0

Fig.3 Location of stimulation sites in MTh

The loci of 141 stimulation sites are plotted on the frontal planes that extend from Fr. 6.5 to 9.0. The closed circles indicate the effective sites of stimulation. Electrical stimulation with pulse trains to those sites resulted in excitation and /or inhibition of the VB neurons. The open circles $(O)$ indicate the ineffective sites of stimulation. VB neuronal activity did not change with stimulation of the ineffective sites. The legend for Table 1 provides the definitions of the anatomical abbreviations. 
Teble 2 Number of each class of response, based on neuronal type

\begin{tabular}{c|cccc|c} 
& \multicolumn{4}{|c|}{ Class of response } & \\
\cline { 2 - 6 } Neuronal type & Class 1 & Class 2 & Class 3 & Class 4 & Total \\
\hline Nociceptive & 53 & 21 & 31 & 96 & 201 \\
Non-nociceptive & 19 & 16 & 29 & 105 & 169
\end{tabular}

$V B \cdot 1$

A

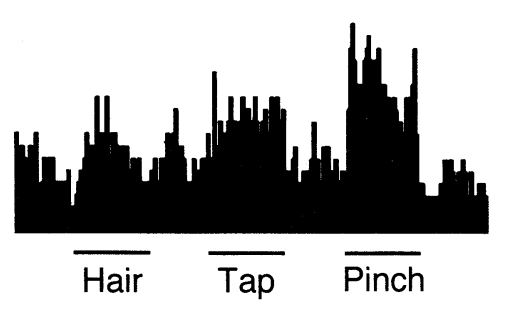

B

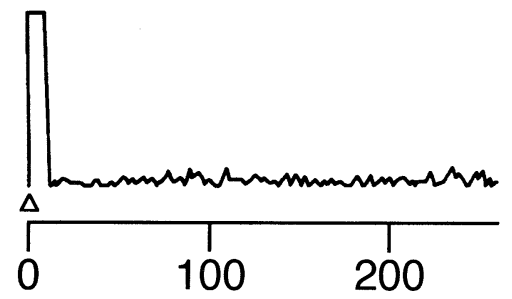

$V B \cdot 2$
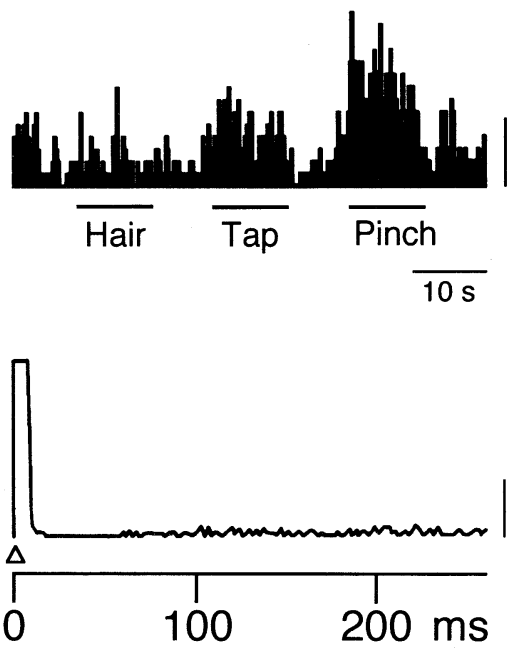

D

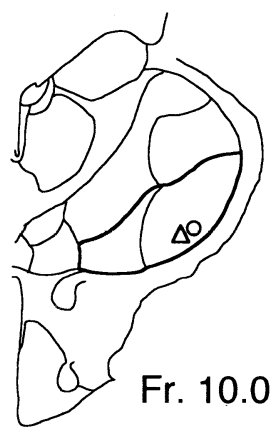

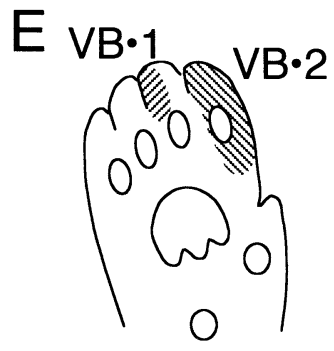

Fr. 8.5

Fig.4 Responses to pulse train stimulation of MTh among simultaneously recorded units

A : sequential histograms of responses to mechanical stimuli of each $\mathrm{Rf}$. "Hair, Tap and Pinch" indicate bending hairs, tapping and pinching skin in Rf, respectively. Vertical bar indicates $20 \mathrm{~Hz}$. B : PSTHs of responses to pulse train stimulation of MTh. Vertical bar indicates 20 spikes. Open triangles $(\triangle)$ show point at which MTh was stimulated. Analysis time is $256 \mathrm{~ms}$ (bin width $=2.0 \mathrm{~ms})$. C and D : site of stimulation in MTh $(\mathbf{O})$ and recording sites of each unit in VB $(\bigcirc, \triangle)$. E : Rfs of each unit. 
VPM stimulation showed that the distribution of response class differed significantly between VPM stimulation and CL, CM or MD stimulation ( $\chi^{2}$ test, $\mathrm{p}<0.05$ ).

Figure 3 shows the location of stimulation sites in the MTh. The 141 stimulating loci are plotted on the frontal planes that extend from Fr. 6.5 to 9.0. The effective sites at which electrical stimulation resulted in excitation and /or inhibition of the VB neuronal activities were spread out over the MTh, particularly in the ventral portion of the $\mathrm{CM}$ and the medial portion of the VPM (VPMpc). The sites at which VB neuronal activity did not change by stimulation were found primarily in the posteromedial and dorsal portions of the CM, and MD, and no such ineffective site was found in the VPM.

The relationship between nociceptive input to the VB neurons and the effect of MTh stimulation is shown in Table 2. The distribution of the number of each response class in the nociceptive neurons differed significantly from that in the non-nociceptive neurons ( $\chi^{2}$ test, $\mathrm{p}<0.05$ ).

The effects of MTh stimulation differed between simultaneously recorded nociceptive VB neurons even when their Rfs and recording sites were in close proximity (Fig. 4). Figure 4A shows the response of the units to mechanical stimuli of each Rf. The VB· 1 unit responded weakly to bending the hair and best to pinching the skin. The VB· 2 unit exhibited moderate response to tapping the skin and better response to pinching the skin, but no response to bending the hair. Figure $4 \mathrm{~B}$ shows the responses of those units to MTh stimulation. The VB 1 unit showed no change in neuronal activity by MTh stimulation. In contrast, inhibition of spontaneous discharge that had a latency of $16 \mathrm{~ms}$ and lasted for $40 \mathrm{~ms}$ was observed in the VB.2 unit as a result of MTh stimulation.

3) Effect of MTh stimulation on response of VB neuron to Rf stimulation.

The effect of MTh stimulation on the response to Rf stimulation was examined in 94 units. An inhibitory effect on the response to electrical stimulation applied to the center of the Rf (cRf) due to MTh stimulation was observed in 27 of the 94 units. The inhibitory effect was observed when electrical stimulation was applied to the CM, VPM and Spf. In 39 units, the discharge evoked by $c R f$ stimulation was not inhibited, even when the spontaneous discharge was suppressed by MTh stimulation.

Figure 5 shows effects of VPMpc stimulation on responses to stimulation of each $\mathrm{cRf}$ in the simultaneously recorded neurons. The $\mathrm{VB} \cdot 1$ unit responded to cRf stimulation and exhibited moderate inhibition of spontaneous discharge for a duration of $55 \mathrm{~ms}$ as a result of VPMpc stimulation. Based on the change in the interval between $c R f$ and VPMpc stimuli, the response of cRf stimulation was suppressed gradually by VPMpc stimulation and was completely inhibited when electrical stimulation was applied to VPMpc 40 and $60 \mathrm{~ms}$ prior to cRf stimulation (Fig. 5A -40 and $-60 \mathrm{~ms}$ ). On the other hand, the $\mathrm{VB} \cdot 2$ unit responded to $\mathrm{cRf}$ stimulation, and exhibited inhibition of spontaneous discharge for a duration of $40 \mathrm{~ms}$ and weak excitation with two components of discharge following the inhibition as a result of VPMpc stimulation. The fast component had a latency ranging from 58 to 88 $\mathrm{ms}$ and the late component had a latency ranging from 124 to $146 \mathrm{~ms}$. The response of the $\mathrm{VB} \cdot 2$ unit to cRf stimulation was not affected even when the interval between cRf and VPMpc stimuli was variously changed. The fast component of evoked discharge by VPMpc stimulation was completely inhibited when electrical stimulation was applied to the VPMpc 40 and $60 \mathrm{~ms}$ prior to Rf stimulation (Fig. 5A-40 and-60 ms). The late component was also inhibited when electrical stimulation was applied to the 


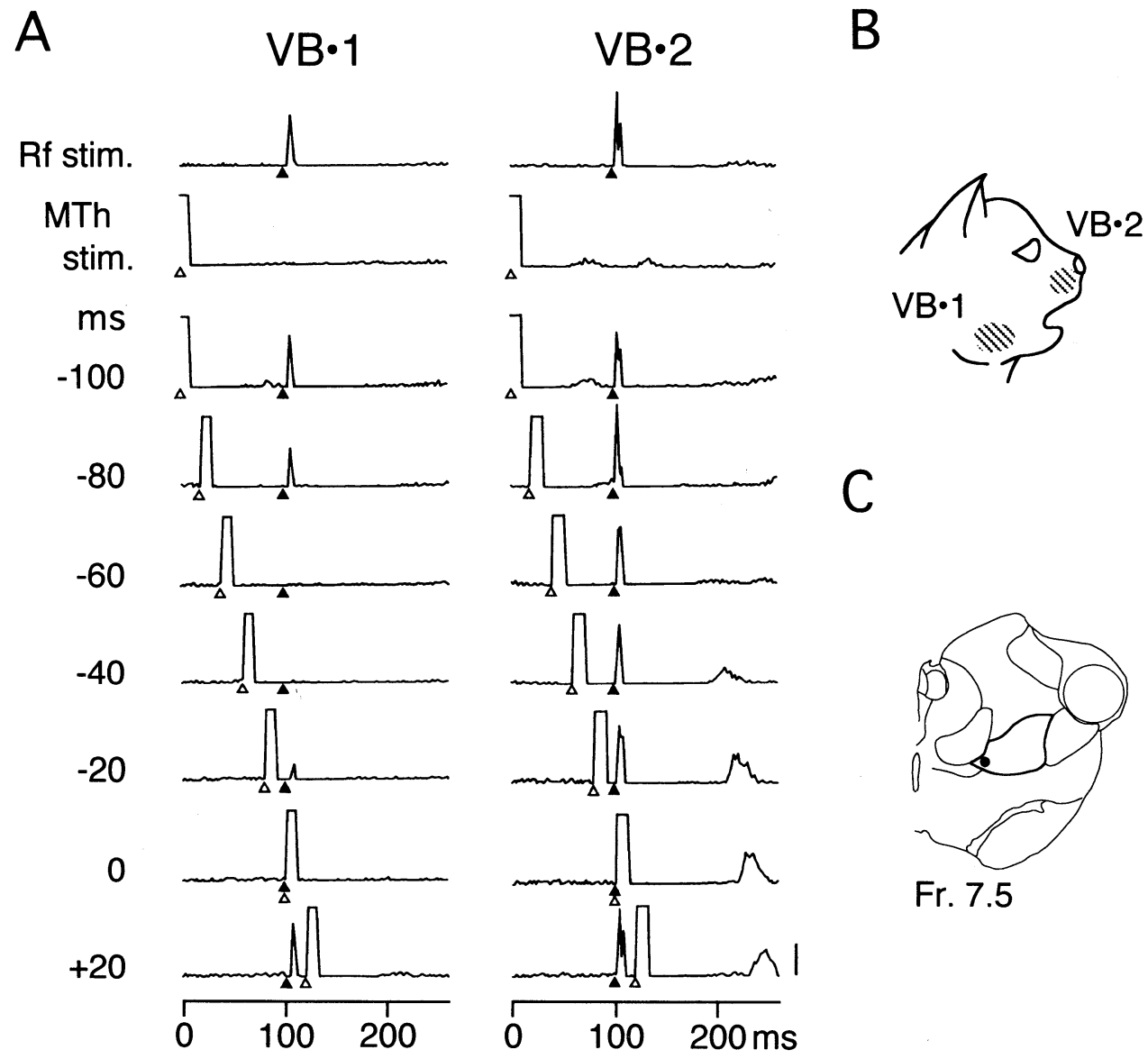

Fig.5 Effect of MTh stimulation on responses evoked by Rf stimulation among simultaneously recorded units

A : PSTHs of responses to double shock of Rf and MTh. Numbers of left indicate intervals between stimulation of Rf and MTh. When MTh was stimulated before Rf, numbers are expressed with a minus sign. Open triangles $(\triangle)$ show point at which MTh was stimulated. Closed triangles (A) show point at which Rf was stimulated. Rectangular waves following open triangles indicate stimulus artifacts of pulse train stimulation of MTh. Vertical bar indicates 40 spikes. Analysis time is $256 \mathrm{~ms}$ (bin width $=2.0 \mathrm{~ms}$ ) B : Rfs of each unit. C $:$ site of stimulation in MTh.

VPMpc 80 and $100 \mathrm{~ms}$ prior to cRf stimulation (Fig. 5A-80 and-100ms). Furthermore, the late component was facilitated by cRf stimulation (Fig. 5A -20, 0 and $+20 \mathrm{~ms}$ ). The latency of the late component of the $\mathrm{VB} \cdot 2$ unit response to MTh stimulation was unstable during doubleshock testing.

Despite the lack of an inhibitory effect of MTh stimulation on the response to cRf stimulation, the response to stimulation of the periphery of the Rf (pRf) was suppressed by MTh stimulation in some experiments. Figure 6 shows an example of the inhibitory effect on the response to stimulation of the $\mathrm{pRf}$ when a conditioning stimulation was applied to the VPMpc. The spontaneous discharge of this unit inhibited by VPMpc stimulation (Fig. 6A and 6B). The response of the unit to $\mathrm{cRf}$ stimulation was not suppressed even when the interval of those stimuli was variously changed (Fig. 6A). On the other hand, the response of the unit to $\mathrm{pRf}$ stimulation was inhibited completely when electrical stimulation was applied to the VPMpc $60 \mathrm{~ms}$ prior to Rf stimulation (Fig. $6 \mathrm{~B}-60 \mathrm{~ms}$ ). 


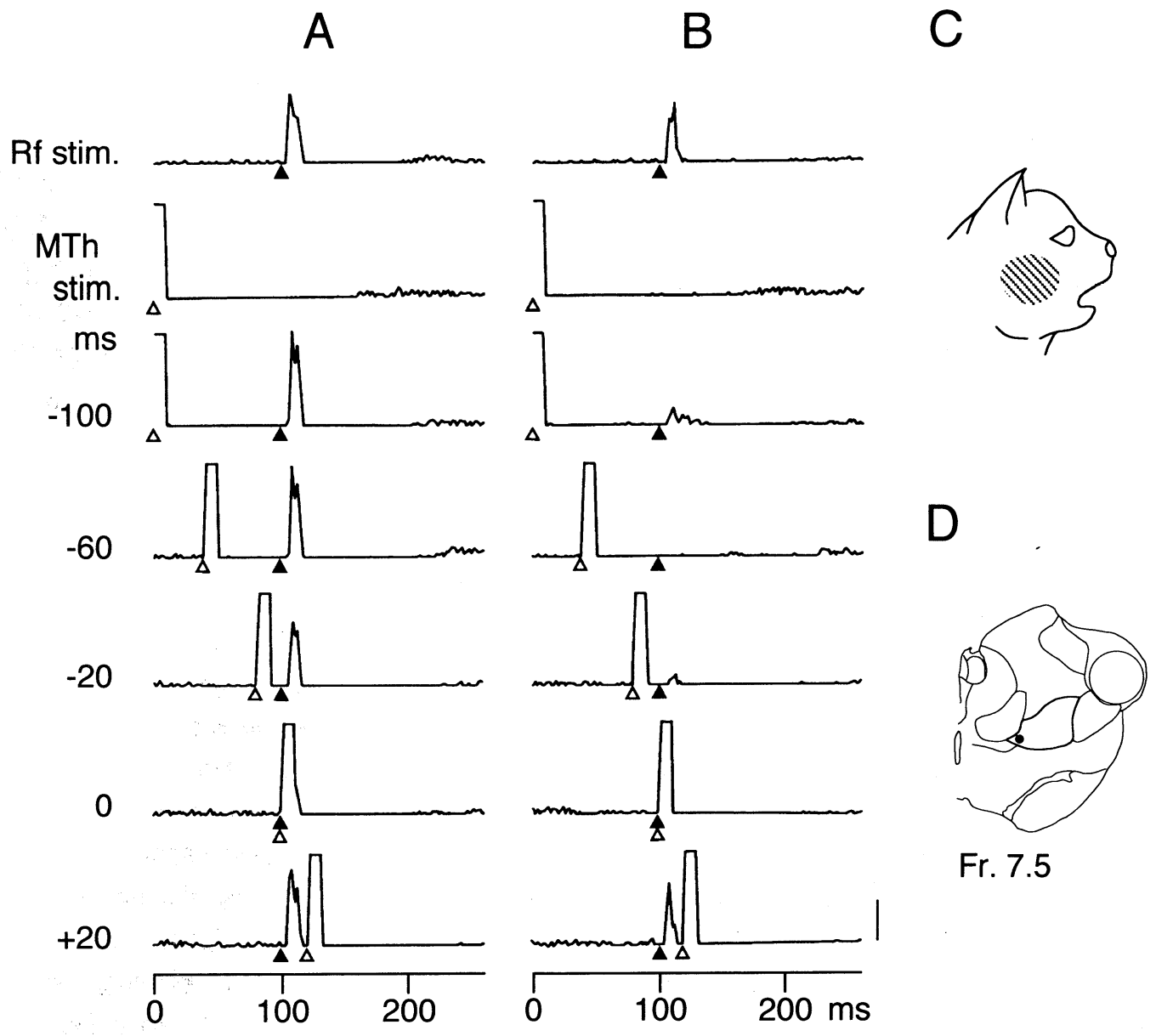

Fig.6 Difference in effect of MTh stimulation on responses evoked by Rf stimulation according to change in site of stimulation in the Rf

A and B : PSTHs of responses to double shocks of MTh and center of Rf, and periphery, respectively. Analysis time is 256 $\mathrm{ms}$ (bin width $=2.0 \mathrm{~ms}$ ). The legend for Figure 5 provides the definitions of numbers on left and symbols. $\mathrm{C}: \mathrm{Rf}$ of the unit. D : site of stimulation in MTh.

\section{Discussion}

Interactions among the somatosensory inputs at the thalamic level have been studied frequently using the evoked response ${ }^{3,9,10}$. In contrast, the effects of thalamic stimulation on spontaneous thalamic neuronal activity have not been studied extensively. Using test stimulation of the spinothalamic tract and thalamic conditioning stimulation, Ishijima and $\mathrm{Sano}^{3)}$ reported interactions at the thalamic level. The potentials evoked by spinothalamic tract stimulation in the ventral posterior lateral nucleus (VPL) neuron was facilitated by a conditioning stimulation of $300 \mathrm{~Hz}$ applied to the CL, CM and $\mathrm{MD}^{3}$. The facilitatory effect was prominent when the $\mathrm{CM}$ and $\mathrm{CL}$ were stimulated ${ }^{3)}$. In contrast, the potentials of non-specific nuclei evoked by spinothalamic tract stimulation was suppressed by VPL stimulation, and this inhibitory effect lasted for $200 \mathrm{~ms}$, most remarkably from 30 to $100 \mathrm{~ms}^{3}$. Maekawa and Purpura ${ }^{10)}$ reported that stimulation of the MTh frequently induced an 
inhibitory effect on the response of VB neurons to medial lemniscus stimulation, although in some neurons the response was facilitated. Olausson et al. ${ }^{\text {) }}$ further reported differences in the effects of CL conditioning stimulation on the nociceptive response of VB neurons to the pulp electrical stimulation when the stimulation site in the $\mathrm{CL}$ was altered. In the preceding companion paper ${ }^{11}$, we reported that the effects of CM stimulation on VB neuronal activity differ even between simultaneously recorded neurons in which the Rfs and recording site were in close proximity. Furthermore, the VB neurons were divided into the same four classes reported herein based on the response type to $\mathrm{CM}$ stimulation $^{11}$. In the present study, the response of the VB neuron to stimulation applied to other nuclei in the MTh could be also divided into the same four classes. Because each nucleus of the MTh demonstrated more than one class of response, the nuclei do not appear to exert a specific effect on VB neuronal activity, and a large component of the MTh may be involved in the somatosensory system through complex mechanisms. As shown in Table 1 and Figure 3, the distribution of the response classes in the VPM differed from those in the CL, CM and MD, and the effective stimulation sites were found primarily in the medial portion of the VPM and the ventral portion of the CM. Moreover, many of the sites of ineffective stimulation were located in the MD. These results support in part the findings of Ishijima and Sano and suggest that the medial portion of the VPM and the ventral portion of the CM appear to have similar function with respect to the modification of somatosensory information. The medial portion of the VPM is composed of small cells and is widely regarded as a thalamic relay station in the gustatory pathway. However, this portion sends fibers not only to the gustatory area but also to the intralaminar nuclei, the lateral portion of the
VPM and the MD ${ }^{14}$.

As shown in Table 2, MTh stimulation was more effective in nociceptive neurons than in non-nociceptive neurons. However, the effects of MTh stimulation differed among the simultaneously recorded nociceptive units even when their Rfs and recording sites were in close proximity (Fig. 4). These results indicate that the effects depend on not only responsive nature to nociceptive stimulation but also other VB neuronal characteristics.

Electrophysiological and histological studies indicate that the MTh receives afferents from the spinothalamic tract and the brain stem reticular structures ${ }^{15-18}$. In addition, Giesler et al. ${ }^{19)}$ revealed a projection of spinothalamic tract cells to the MTh, indicating that these cells are involved in the ascending tracts that activate neurons of the reticular formation. Although efferents of the MTh are variant in each nucleus, the common projection site appears to be the cerebral cortex ${ }^{20,21}$. The reticular nucleus (Rt) of the thalamus connects with many nuclei of the dorsal thalamus ${ }^{22}$. Olausson et al. ${ }^{9}$ ) suggested that since the inhibitory and facilitatory effects of $\mathrm{CL}$ stimulation on the VB neuronal activity started at a mean delay of $6.8 \mathrm{~ms}$ (range 5-10 ms) and 11 ms (range 5-20 ms), respectively, and did not reduce after application of lidocaine to the suprasylvian gyrus, these effects are mediated via the Rt of the thalamus at the VB. Chang et al. ${ }^{23)}$ and Lo et al. ${ }^{24)}$ reported that CM stimulation inhibited the response of Pf neurons to noxious stimulation and spontaneous discharge of cortical neurons. This inhibitory effect was observed after a delay of $10-20 \mathrm{~ms}^{24}$. Furthermore, they indicated that the cortical response with pronounced IPSP was obtained only upon stimulation of the CM and Rt of the thalamus ${ }^{23}$. These responses were similar except for the latency ${ }^{23}$. Based on the above results, they suggested that the inhibitory effect of CM 
stimulation is involved in the Rt of the thalamus and cerebral cortex ${ }^{23}$. In the present study, the latency of inhibition of spontaneous discharge resulting from MTh stimulation was approximately $20 \mathrm{~ms}$. Since this value is close to the previously reported values by Olausson et al. ${ }^{9}$ and Lo et al. ${ }^{24)}$, the inhibitory effect observed in the present study appears to be mediated via the cortex and/or the Rt of the thalamus on the VB neurons. Previous reports have also suggested that inhibitory control from the cortex and Rt of the thalamus exerts an influence on VB neuronal activity ${ }^{25-27)}$. However, the brain stem reticular system can alter the neuronal activity in both the MTh and $\mathrm{VB}^{28}$. Schieppati et al. ${ }^{29)}$ reported that the bulbar and mesencephalic reticular formation exert differential effects on the response to peripheral stimulation of the VPL neurons; stimulation of the former inhibited neuronal activity including spontaneous discharge and stimulation of the latter facilitated evoked discharge. They suggested that the inhibitory effect of the bulbar descends to act on the dorsal column nuclei and the facilitation is due to inhibition of neuronal activity in the Rt which exerts inhibitory control on the VPL neuron ${ }^{29}$. In the present study, inhibitory effects on the VB spontaneous and evoked discharge were observed, as well as an excitatory response in the VB neurons. Although the mechanism associated with the effects of MTh stimulation can not be assumed to be the same as the neuronal circuits suggested by Schieppati et al., the brain stem reticular formation may participate in the mechanism associated with the excitatory response of VB neurons to MTh stimulation because the discharges induced by MTh stimulation had a long and unstable latency.

Iwamura and Inubushi ${ }^{30,31)}$ reported that excitatory and inhibitory response patterns of VB neuron to Rf stimulation differed according to change in stimulation site within the Rf. The convergence of inputs from both spinothalamic tract and dorsal column nuclei onto the same VB neuron was reported by Ma et al. ${ }^{32}$. Ralston III and Ralston ${ }^{33}$ also demonstrated that inputs from dorsal column nuclei to VB neurons had substantial interactions with GABA immunoreactivity interneurons, and spinothalamic tract inputs had less interactions with them. As shown in Figure 6, inhibition of the response to cRf stimulation was not observed, even when the response to $\mathrm{pRf}$ stimulation inhibited completely by MTh stimulation. Although we do not demonstrate that a pathway from the cRf to the VB is different than a pathway from the pRf, this result suggests that different inputs from the periphery converge on the same VB neuron and that the mechanism of the inhibition at the VB neuron differs among the inputs. Moreover, since the inhibitory effect on spontaneous discharge was more pronounced than that on the evoked discharge, the MTh appear to modify level of VB neuronal activity, particularly in the resting condition.

Follett and Mann ${ }^{34)}$ reported effective stimulation distance for current from macroelectrodes using antidromic response of axons of the pyramidal tract in cat. The effective stimulation distance at current intensity of $0.5 \mathrm{~mA}$ and duration of 0.05 $\mathrm{ms}$ was $0.99 \pm 0.64 \mathrm{~mm}$ and at current intensity of $1.0 \mathrm{~mA}$ was $1.32 \pm 0.74 \mathrm{~mm}^{34}$. The threshold of antidromic response of the axon using $0.05 \mathrm{~ms}$ in duration was approximately 3 times threshold measured using $0.5 \mathrm{~ms}$ in duration ${ }^{34}$. MTh stimulation used in the present study was at 7-10 $\mathrm{V}$ for $0.5 \mathrm{~ms}$ in duration and the estimated current intensity of them was approximately 170$240 \mu \mathrm{A}$. Although there is no denying that axons passing through the MTh may be activated by electrical stimulation of the MTh, effective stimulation distance of the MTh stimulation appear to be approximately 1.0-1.5 $\mathrm{mm}$.

Thus, not only the CM but also other MTh 
nuclei are able to modify VB neuronal activity. The MTh may be involved in pain inhibitory systems, probably in the motivational-affective aspects of pain. The neuronal network between the MTh and the VB appears to be indirect and which include the cortex and/or reticular system.

\section{Acknowledgment}

This work was supported in part by grant from Kitasato University (Grant-in-Aid No. SAHSC113-1995 and No. SAHS-C116-1996).

\section{References}

1) Morison, R. S. and Dempsey, E. W.: A study of thalamo-cortical relations. Am. J. Physiol., 135: 281-292, 1942

2 ) Dong. W. K., Ryu, H. and Wagman, I. H.: Nociceptive responses of neurons in medial thalamus and their relationship to spinothalamic pathways. J. Neurophysiol., 41: 1592-1613, 1978

3 ) Ishijima, B. and Sano, K.: Responses of specific and nonspecific thalamic nuclei to the selective $\mathrm{A}-\delta$ and $\mathrm{C}$-fiber stimulation, and their interaction in cat's brain. Proceedings of the xxxth Annual Meeting of the Japan Neurosurgical Society, 84-100, 1971

4) Poggio, G. F. and Mountcastle, V. B.: A study of the functional contributions of the lemniscal and spinothalamic systems to somatic sensibility. Johns Hopk. Hsp. Bull., 106: 266-316, 1960

5 ) Dostrovsky, J. O. and Guilbaud, G.: Noxious stimuli excite neurons in nucleus submedius of the normal and arthritic rat. Brain Res., 460: 269-280, 1988

6 ) Kenshalo, D. R. Jr., Giesler, G. J., Leonard, R. B. and Willis, W. D.: Responses of neurons in primate ventral posterior lateral nucleus to noxious stimuli. J. Neurophysiol., 43: 15941614,1980
7 ) Linzer, M. and Van Atta, L.: Effects of acupuncture stimulation on activity of single thalamic neurons in the cat. In J.J.Bonica (Ed.) Advances in Neurology, Vol. 4, Raven Press, New York, 799-811, 1974

8 ) Sumiya, E. and Kawakita, K.: Inhibitory effects of acupuncture manipulation and focal electrical stimulation of the nucleus submedius on a viscerosomatic reflex in anesthetized rats. Jpn. J. Physiol., 47: 121130, 1997

9 ) Olausson, B., Shyu, B.-C., Rydenhag, B. and Andersson, S.: Thalamic nociceptive mechanisms in cats, influenced by central conditioning stimuli. Acta Physiol. Scand., 146: 49-59, 1992

10) Maekawa, K. and Purpura, D. P.: Intracellular study of lemniscal and non-specific synaptic interactions in thalamic ventrobasal neurons. Brain Res., 4: 308-323, 1967

11) Ogata, M., Noda, K., Akita, H. and Aikawa, S.: Effect of electrical stimulation of the centre médian nucleus on neuronal activity of the thalamic ventrobasal complex in the anesthetized cat. J. Jap. Soci. Acu. (in press)

12) Saburi, M., Niki, K., Kobayashi, S. and Aikawa, S.: A magnetically coupled multimicroelectrode system. IEEE Transactions on Biomedical Engineering, 30: 341-346, 1983

13) Jasper, H. H. and Ajmone-Marsan, C.: A stereotaxic atlas of the diencephalon of the cat. Ottawa: National Research Council Canada, 1954

14) Abe, K.: An experimental-anatomical study on the intrathalamic fiber connections of the posterior ventral nuclei in the cat. OkayamaIgakkai-Zasshi, 84: 11-23, 1972

15) Mantyh, P. W.: The terminations of the spinothalamic tract in the cat, Neurosci. Lett., 38: 119-124, 1983

16) Holloway, J. A., Fox, R. E. and Iggo, A.: 
Projections of the spinothalamic tract to the thalamic nuclei of the cat. Brain Res., 157: 336-340, 1978

17) Robertson, R. T. and Feiner, A. R.: Diencephalic projections from the pontine reticular formation: autoradiographic studies in the cat. Brain Res., 239: 3-16, 1982

18) Scheibel, M. E. and Scheibel, A. B.: Patterns of organization in specific and nonspecific thalamic fields. In D. P. Purpura and M. D. Yahr (Eds.) The Thalamus, Columbia Univ. Press, New York, 13-46, 1966

19) Giesler, G. L. Jr., Yezierski, R. P., Gerhart, K. D. and Willis, W. D.: Spinothalamic tract neurons that project to medial and/or lateral thalamic nuclei: evidence for a physiologically novel population of spinal cord neurons. J. Neurophysiol., 46: 1285-1307, 1981

20) Bentivoglio, M., Molinari, M., Minciacchi, D. and Macchi, G.: Organization of the cortical projections of the posterior complex and intralaminar nuclei of the thalamus as studied by means of retrograde tracers. In G. Macchi et al.(Eds.) Somatosensory integration in the thalamus, Elsevier Publ. Co., Amsterdam, 337-363, 1983

21) Jones, E. G,: Mediodorsal nucleus, In E. G. Jones (Eds.), The thalamus, Plenum Press, New York and London, 649-664, 1985

22) Jones, E. G.: Some aspects of the organization of the thalamic reticular complex. J. Comp. Neurol., 162: 285-308, 1975

23) Chang, H. T., He, S. and Chen, G.: A prosencephalic neuronal circuit possibly involved in modulation of pain. Sci. Sinica, 27: 48-60, 1984

24) Lo, F.-S., Yün, C.-S., Yang, S.-L., Tuanmu, C.H. and Chang, H.-T.: Inhibition of nociceptive discharges of parafascicular neurons by direct electrical stimulation of nucleus centrum medianum. Sci. Sinica, 21: 533-544, 1978
25) Aikawa, S.: The inhibitory effect of somatosensory cortex to ventrobasal thalamic neurons. Bul. Seishin-igaku Institute, 11:31-36, 1964

26) Peschanski, M., Guilbaud, G. and Gautron, M.: Neuronal responses to cutaneous electrical and noxious mechanical stimuli in the nucleus reticularis thalami of the rat. Neurosci. Lett., 20: 165-170, 1980

27) Sotgiu, M. L., Marini, G., Esposti, D. and Fava, E.: A horseradish peroxidase study of afferent projections to nucleus reticularis thalami in the cat. Arch. Ital. Biol., 119: 151159,1981

28) Mancia, M., Mariotti, M. and Schieppati, M.: Brain stem reticular control of thalamic integration. In G. Macchi et al. (Eds) Somatosensory integration in the thalamus, Elsevier Publ. Co., Amsterdam, 183-195, 1983

29) Schieppati, M., Mariotti, M., Arosio, M. and Cenzato, M.: Mesencephalic and bulbar reticular formation influences of somatosensory transmission though the thalamus. Electroenceph. clin. Neurophysiol., 53: 338-342, 1982

30) Iwamura, Y. and Inubushi, S.: Regional diversity in excitatory and inhibitory receptive-field organization of cat thalamic ventrobasal neurons. J. Neurophysiol., 37: 910-919, 1974

31) Iwamura, Y. and Inubushi, S.: Functional organization of receptive fields in thalamic ventrobasal neurons examined by neuronal response to iterative electrical stimulation of skin. J. Neurophysiol., 37: 920-926, 1974

32) Ma, W., Peschanski, M. and Ralston III, H. J.: The differential synaptic organization of the spinal and lemniscal projections to the ventrobasal complex of the rat thalamus. Evidence for convergence of the two systems upon single thalamic neurons. Neuroscience, 22: 925-934, 1987

33) Ralston III, H. J. and Ralston, D. D.: Medial lemniscal and spinal projections to the 
macaque thalamus: An electron microscopic study of differing GABAergic circuitry serving thalamic somatosensory mechanisms. J. Neuroscience, 14:2485-2502, 1994

34) Follett, K. A. and Mann, M. D.: Effective stimulation distance for current from macroelectrodes. Exp. Neurol., 92: 75-91, 1986 


\section{麻酔ネコ視床腹側基底核ニューロン活動に対する 内側視床核通電刺激の影響}

緒形雅則 野田和子 秋田久直 相川貞男

北里大学医療衛生学部生理学研究室

要 旨

内側視床諸核の視床体性感覚系への干涉作用を検討するために本実験を行った。ネコ視床腹側基底核 群よりマルチ微小電極法により複数個のニューロン活動を細胞外同時導出した。導出したユニット活動 に対する内側視床核通電刺激効果について検討した結果、興奮性、抑制性、抑制および興奮性と影響 なしの 4 タイプの反応が認められた。また内側視床内の複数の核で上記 4 タイプの反応が観察され、核 による特異性は認められなかった。また、末梢求心性入力に対する内側視床核刺激の抑制効果も複数の 核でみられ、さらに入力種による影響の差異も観察された。以上の如く、内側視床内の広い領域が体性 感覚情報の調節に関与しうることが示唆された。

キーワード : 視床、腹側基底核群、内側視床、電気刺激、体性感覚 